gyrie) und ein Klaffen der Juctus prostatici dureh Narbenprozesse nach dem cudoskopisehen Bilde chenfalis nicht vorlag, stellten wir die Diagnose auf Corpora amylacea in den Ausfiihrungsgängen, obwohl dureh Aus. krat\%ung sich keines der Corpora gewinnen ließ, weil diese wohl zu tief oder zu fest siakir.

bic Bilder sind mit dom Wossidloschen Endoskop fiur die Pary posterior wethras: alufgenommen und ron Herm Maler Haase angefertigt worden.

\title{
Ueber Corpora amylacea im endoskopischen Befunde der hinteren Harnröhre.
}

Mit einer Kunstbeilage.

Von Dr. (otto Loose und Dr. Erich Steffen, Spezialärzten für L'rologie in Berlin.

In Nr. 3 dieser Wochensehrift hat Pfist.r. in einem Aufsat\% "T'ober" Prostataclemente bei L'rethrorrhoea ex libidine" darauf hingewiesen. daß bei älteren Ieuten (orpora amvlacea sowoll in den I)rüsen als anch in den Ausführungsgängen, aber anch frei in der l'rethri, namentlieh in der Lmgebung des Colliculus seminalis, liegen kömnen. Pfister hält e $s$ in rinem angeführten lall ron Urethrorrhoea $\mathrm{ex}$ libidine für wahr. scheinlich, unseres Frachtens mit Recht, daß solche in der Lrethri posterior deponierten Körnchen mit Drüsensekret nach vorn getragen wurden und bei der mikroskopisehen Entersuehung des Urethralsekretes \%utage traten. An Schlnß seines Artikels bedauert Pfist.cr, daß eine Luloskopic der hinteren Harnröhre, die , Klarlıeit gebracht hätte“" unterbleiben mußte. Wir hatten nun vor längerer Zeit Gelegenheit, cincen solehen Fall \%u endoskopieren und den merkwürdigen Befund im farbigen Bild aufnchmen z.u lassen. Jie Wiedergabe der untenstehenden Bilder, als Ergänzung des Pfistersehen Artikels und Beweis seiner Hypothese, erschien uns voll allgenteinem Interesse.

Bild I gibt die Partie der hinteren Harnröhre dicht vor dem Colliculus seminalis. Wir sehen die Crista colliculi mit zahlreichen kleineren und größeren, bräunlich sehwarzen lilecken besät. Für den nicht mit der Fndoseopia posterior Vertrauten sei hinzugefügt, daß es sich noch nicht ım den Colliculus selbst, sondern um dic hier stärker entwickelte Sehleimhautleiste haudelt, welehe proximalwärts auf den Collieuhs hinführt.

Bild II zeigt den Colliculus selbst mit seiner Ungebung. Auch lier die bräunlich-sehwarzen Flecken. Noeh ist dic Kuppe des Sanrenhügels fleekenfrei.

Unseres Erachtens sitzen die Konkrentente (denn das bedeuten dic Flecken) in den Ductus prostatiei. Die Partie der Harnröhre hinter dem Collieulus bis zun Blasenhalse war fleckenfrei. Was die klinische Scite des falles anlangt, so handelt es sieh un einen 57 jälrigen Patienten, der über blutige Tingierung des Samens und geringe Schmer\%en bei der Ejakulation klagte. Eine Prostatitis oder Entroündung der Samenblasen bestand nicht. Jie Symptome unseres Falles können daher auf Iäsionen der Śchleimhaut dureh die Konkremente bei der Ejakulation bezogen worden. Der Urinbefund war normal. Da eine Argyrie der Sichleimhaut auszuschließen war (Patient wurde weder von uns noeh von anderer Seite vorher init Argentum behiundelt, auch die vordere Harnröhre zeigte nichts von $\mathrm{Ar}$. 